\title{
The staphylococci and staphylococcal pathogenesis
}

\author{
Martin J. McGavin* and David E. Heinrichs*
}

Department of Microbiology and Immunology, Western University, London, ON, Canada

*Correspondence: mmcgavin@uwo.ca; deh@uwo.ca

Over the past 30 years, the scientific literature has been rife with articles that have chronicled the enduring threat and changing nature of Staphylococcus aureus as a leading cause of infectious morbidity and mortality to humans (Sheagren, 1984; Archer, 1998; Lowy, 1998; Otto, 2010). The most current surveys indicate that $S$. aureusis responsible for almost 500,000 hospitalizations and 30,000 deaths annually in the USA (Klein et al., 2007). At the turn of the twentieth century, the major threat was hospital-associated strains of methicillin resistant S. aureus (HA-MRSA) that are resistant to multiple antibiotics, and reports that some had acquired high level vancomycin resistance (Pearson, 2002; Weigel et al., 2003) seemed to assure the inevitable proliferation of strains that are resistant to all antibiotics. Although this crisis has not yet materialized, we have instead experienced the sudden emergence and global dissemination of hyper-virulent strains of community acquired MRSA (CA-MRSA). Another unexpected threat was the emergence of CA-MRSA in animal adapted strains of $S$. aureus, and their zoonotic transmission to humans. Conversely, some livestockassociated strains have undergone a recent evolutionary transition from human to animal hosts. Amidst this backdrop of newly emergent strains, common clonal types of HA-MRSA and methicillin susceptible S. aureus (MSSA) persist in their threat to health care, and attempts to lessen the impact through vaccine development have thus far been unsuccessful.

In this Special Topics issue, recent advances in Staphylococcal research are captured in a collection of research, review, opinion, and methods articles, which we have assigned to the general themes of vaccine development, virulence, and immune evasion, metabolic activity in response to host environment, methods development, and comparative genomics and genome evolution.

\section{VACCINE DEVELOPMENT}

On the front lines of vaccine development, an opinion article from Bagnoli et al. (2012) at Novartis offers plausible explanations for the vaccine failures that have plagued human clinical trials, and offer optimism that success can be achieved with an appropriate multivalent vaccine that stimulates cellular immunity and opsonophagocytosis, while inhibiting bacterial viability and/or toxicity. Pancari et al. (2012) outline the vaccine strategy and progress at Merck Research labs, defining the mechanistic basis of protection offered by a vaccine that targets the IsdB protein, which is expressed in vivo under iron-limited growth conditions.

\section{METABOLIC ACTIVITY IN RESPONSE TO HOST ENVIRONMENT}

The host environment imposes many stresses on bacteria, among them nutrient limitation and oxidative stress imparted by host phagocytes. Proteins involved in iron acquisition are attractive vaccine components, because their expression is promoted by growth in the iron-restricted host environment. Sheldon and Heinrichs (2012) review the biogenesis, substrate specificity, and impact on host innate immune response, of cell envelope lipoproteins that are up-regulated in response to low iron. Gaupp et al. (2012) summarize the cellular targets of oxidative stress, mechanisms employed to sense oxidative stress and damage, oxidative stress protection and repair mechanisms, and regulation of the oxidative stress response. Original research by Fuller et al. (2011) defines the role of a lactate-quinone oxidoreductase (Lqo) in countering oxidative stress imposed by host phagocyte derived nitric oxide, and show that this cytoplasmic protein is essential for virulence in a murine model of sepsis, particularly in association with myocarditis.

\section{VIRULENCE STUDIES}

Although most manifestations of $S$. aureus disease are attributed to its growth as an "extracellular" pathogen, it is gaining new respect for its ability to survive within host cells as a facultative intracellular pathogen. Fraunholz and Sinha (2012) present a guide to recent developments in this emerging field of study, summarizing the variety of intracellular fates of $S$. aureus, including artwork that appears on the cover of this issue. Original research by Spaulding et al. (2012) shows that major clonal types of S. aureus known for causing hospital and community acquired infections, exhibit distinct differences in their capacity for cardiotropic versus lethal sepsis infections, and that production of superantigen toxins and cytolysins account for some of these differences. Expanding on the theme that some strains specialize in certain types of infection, Anderson et al. (2012) describe an ex vivo porcine vaginal mucosa model to evaluate the contribution of cytolysins in biofilm formation and tissue damage caused by $S$. aureus strains associated with menstrual toxic shock syndrome. Xu and McCormick (2012) review molecular biology of staphylococcal superantigen toxins, including toxic shock syndrome toxin TSST, and offer a unique perspective on superantigen toxins, which includes a proposed role in colonization, in addition to disease progression. Vandenesch et al. review developments in understanding the potentially redundant arsenal of membrane-damaging virulence factors at the disposal of S. aureus, and their interplay with the host immune system (Vandenesch et al., 2012). Hanke and Kielian (2012) have authored a review that summarizes the immune defenses that staphylococcal biofilms evade, and place specific emphasis on the idea that staphylococcal biofilms skew the host immune response away from a proinflammatory bactericidal phenotype toward an antiinflammatory, pro-fibrotic response that favors bacterial persistence.

\section{GENE REGULATION}

An emerging theme in regulation of gene expression by microbial pathogens is that of regulatory RNA's and control of RNA stability. Morrison et al. (2012) extend this theme, identifying a new role for the SarA transcriptional regulator of $S$. aureus, in binding to and altering the mRNA turnover properties of target transcripts. Cue et al. (2012) 
review how various regulatory factors affect production of poly $\mathrm{N}$-acetyl glucosamine, an intercellular polysaccharide adhesin that contributes to biofilm related infections in both S. aureus and S. epidermidis.

\section{METHODS}

An increasing appreciation of the role of biofilms in persistent infection and immune evasion highlights the importance of standard techniques to evaluate biofilm structure and genetics of biofilm formation. Walker and Horswill (2012) describe a simple method for quantitative evaluation of $S$. aureus biofilms on glass coverslips coated with human plasma. Our current and future knowledge of gene function could not be achieved without the less heralded development of efficient techniques for construction of gene deletion mutations. Monk and Foster (2012) review the restriction-modification barrier in Staphylococci, and how knowledge of these systems can be used to develop plasmid vectors that can be used to manipulate previously un-transformable strains.

\section{COMPARATIVE GENOMICS AND EVOLUTION}

A comparative genomics evaluation by Ben Zakour et al. (2012) identifies new directions for research into pathogenesis and patho-adaptation of the S. intermedius group of animal pathogens, revealing extensive differences in the accessory genome content between closely related species that nevertheless inhabit distinct host niches. Research by McGavin et al. (2012) reveal three distinct clades within $S$. aureus clonal complex CC30, of which Clade 3 comprised of hospital-associated strains exhibit numerous features that are consistent with evolution through niche adaptation mechanisms. Finally, McCarthy et al. (2012) have analyzed 79 sequenced $S$. aureus genomes to assess the role of bacteriophage in dissemination of toxins and immune evasion genes, finding that horizontal transfer is restricted by bacteriophage family, and lineage of the host bacterium.

\section{REFERENCES}

Anderson, M. J., Lin, Y.-C., Gillman, A. N., Parks, P. J. Schlievert, P. M., and Peterson, M. (2012). Alphatoxin promotes mucosal biofilm formation by Staphylococcus aureus. Front. Cell. Infect. Microbiol. 2:64. doi: 10.3389/fcimb.2012.00064

Archer, G. L. (1998). Staphylococcus aureus: a well-armed pathogen. Clin. Infect. Dis. 26, 1179-1181.

Bagnoli, F., Bertholet, S., and Grandi, G. (2012). Inferring reasons for the failure of Staphylococcus aureus vaccines in clinical trials. Front. Cell. Infect. Microbiol. 2:16. doi: 10.3389/fcimb.2012.00016

Ben Zakour, N., Beatson, S., Van Den Broek, A., Thoday, K., and Fitzgerald, R. (2012). Comparative genomics of the Staphylococcus intermedius group of animal pathogens. Front. Cell. Infect. Microbiol. 2:44. doi: 10.3389/fcimb.2012.00044

Cue, D. R., Lei, M. G., and Lee, C. (2012). Genetic regulation of the intercellular adhesion locus in staphylococci. Front. Cell. Infect. Microbiol. 2:38. doi: 10.3389/ fcimb. 2012.00038

Fraunholz, M., and Sinha, B. (2012). Intracellular Staphylococcus aureus: live-in and let die. Front. Cell. Infect. Microbiol. 2:43. doi: 10.3389/fcimb. 2012.00043

Fuller, J. R., Vitko, N. P., Perkowski, E. F., Scott, E., Khatri, D., Spontak, J. S., Thurlow, L. R., and Richardson, A. R. (2011). Identification of a lactate-quinone oxidoreductase (Lqo) in Staphylococcus aureus that is essential for virulence. Front. Cell. Infect. Microbiol. 1:19. doi 10.3389/fcimb.2011.00019

Gaupp, R., Ledala, N., and Somerville, G. A. (2012). Staphylococcal response to oxidative stress. Front. Cell. Infect. Microbiol.2:33. doi: 10.3389/fcimb.2012.00033

Hanke, M. L., and Kielian, T. (2012). Deciphering mechanisms of staphylococcal biofilm evasion of host immunity. Front. Cell. Infect. Microbiol. 2:62. doi: $10.3389 /$ fcimb.2012.00062

Klein, E., Smith, D. L., and Laxminarayan, R. (2007) Hospitalizations and deaths caused by methicillinresistant Staphylococcus aureus, United States, 1999 2005. Emerging Infect. Dis. 13, 1840-1846.

Lowy, F. D. (1998). Staphylococcus aureus infections. N Engl. J. Med. 339, 520-532.

McCarthy, A. J., Witney, A. A., and Lindsay, J. A. (2012). Staphylococcus aureus lysogenic bacteriophage: carriage and horizontal gene transfer (HGT) is lineage associated. Front. Cell. Infect. Microbiol. 2:6. doi 10.3389/fcimb.2012.00006

McGavin, M. J., Arsic, B., and Nickerson, N. N. (2012) Evolutionary blueprint for host- and niche-adaptation in Staphylococcus aureus clonal complex CC30. Front. Cell. Infect. Microbiol. 2:48. doi: 10.3389/ fcimb. 2012.00048

Monk, I. R., and Foster, T. J. (2012). Genetic manipulation of Staphylococci? Breaking through the barrier. Front. Cell. Infect. Microbiol. 2:49. doi: 10.3389/ fcimb.2012.00049

Morrison, J. M., Anderson, K. L., Beenken, K. E., Smeltzer M.S., and Dunman, P.M. (2012). The staphylococcal accessory regulator, SarA, is an RNA-binding protein that modulates the mRNA turnover properties of late-exponential and stationary phase Staphylococcus aureus cells. Front. Cell. Infect. Microbiol. 2:26. doi: $10.3389 /$ fcimb. 2012.00026

Otto, M. (2010). Basis of virulence in community-associated methicillin-resistant Staphylococcus aureus. Annu. Rev. Microbiol. 64, 143-162.

Pancari, G., Fan, H., Smith, S., Joshi, A., Haimbach, R., Clark, D., Li, Y., Hua, J., Mckelvey, T., Ou, Y., Drummond, J., Cope, L., Montgomery, D., and Mcneely, T. (2012). Characterization of the mechanism of protection mediated by CS-D7, a monoclonal antibody to Staphylococcus aureus iron regulated surface determinant B (IsdB). Front. Cell. Infect. Microbiol. 2:36. doi: 10.3389/fcimb.2012.00036

Pearson, H. (2002). “Superbug” hurdles key drug barrier. Nature 418, 469.

Sheagren, J. N. (1984). Staphylococcus aureus. The persistent pathogen (first of two parts). N. Engl. J. Med. 310, 1368-1373.

Sheldon, J. R., and Heinrichs, D. E. (2012). The ironregulated staphylococcal lipoproteins. Front. Cell. Infect. Microbiol.2:41. doi: 10.3389/fcimb.2012.00041

Spaulding, A. R., Satterwhite, E. A., Lin, Y.-C., ChuangSmith, O. N., Frank, K. L., Merriman, J. A., Schaefers, M. M., Yarwood, J.M., Peterson, M. L., and Schlievert, P. M. (2012). Comparison of Staphylococcus aureus strains for ability to cause infective endocarditis and lethal sepsis in rabbits. Front. Cell. Infect. Microbiol. 2:18. doi: 10.3389/fcimb.2012.00018

Vandenesch, F., Lina, G., and Henry, T. (2012). Staphylococcus aureus hemolysins, bi-component leukocidins, and cytolytic peptides: a redundant arsenal of membrane-damaging virulence factors? Front. Cell. Inf. Microbio. 2:12. doi: 10.3389/ fcimb. 2012.00012

Walker, J. N., and Horswill, A. R. (2012). A coverslipbased technique for evaluating Staphylococcus aureus biofilm formation on human plasma. Front. Cell. Infect. Microbiol. 2:39. doi: 10.3389/ fcimb.2012.00039

Weigel, L. M., Clewell, D. B., Gill, S. R., Clark, N. C., Mcdougal, L. K., Flannagan, S. E., Kolonay, J. F., Shetty, J., Killgore, G. E., and Tenover, F. C. (2003). Genetic analysis of a high-level vancomycin-resistant isolate of Staphylococcus aureus. Science 302, 1569-1571.

Xu, S. X., and McCormick, J. K. (2012). Staphylococcal superantigens in colonization and disease. Front. Cell. Infect. Microbiol. 2:52. doi: 10.3389/ fcimb.2012.00052

Received: 23 April 2012; accepted: 26 April 2012; published online: 18 May 2012.

Citation: McGavin MJ and Heinrichs DE (2012) The staphylococci and staphylococcal pathogenesis. Front. Cell. Inf. Microbio. 2:66. doi: 10.3389/fcimb.2012.00066

Copyright $(\odot 2012$ McGavin and Heinrichs. This is an openaccess article distributed under the terms of the Creative Commons Attribution Non Commercial License, which permits non-commercial use, distribution, and reproduction in other forums, provided the original authors and source are credited. 